\title{
Espécies novas de Anthodioctes Holmberg e notas sobre alguns Dianthidiini (Hymenoptera, Megachilidae) ${ }^{1}$
}

\author{
Danuncia Urban ${ }^{2}$
}

\begin{abstract}
New species of Anthodioctes Holmberg and notes on some Dianthidiini (Hymenoptera, Megachilidae). The following new species are presented: Anthodioctes rosanae sp. nov. and Anthodioctes ayalai sp. nov. from México and Anthodioctes misiutae sp. nov. from Brazil. The male of Moureanthidium bahianum Urban, 1995 and the female of Ananthidium dilmae Urban, 1990 are described by the first time. Notes and new occurrences of Anthodioctes lunatus (Smith, 1854) are given. KEY WORDS. Hymenoptera, Megachilidae, Dianthidiini, Anthodioctes, taxonomy
\end{abstract}

Três espécies de Anthodioctes Holmberg, 1903 são apresentadas, duas do México: Anthodioctes rosanae sp. nov. e Anthodioctes ayalai sp. nov., e uma do sul do Brasil: Anthodioctes misiutae sp. nov. Pela primeira vez são descritos o macho de Moureanthidium bahianum e a fêmea de Ananthidium dilmae. Completam o trabalho algumas notas sobre Anthodioctes lunatus. O material-tipo das espécies novas está depositado na Coleção de Entomologia Pe. J.S. Moure, Universidade Federal do Paraná, Curitiba, (DZUP).

\section{Anthodioctes ayalai sp. nov.}

Figs 1-3

Diagnose. Genas com carena justaorbital curtíssima e sem área brilhante posteriormente, pouco mais estreitas que os olhos quando vistas de perfil, escutelo com amarelo e o metasoma, com predominância do amarelo a partir do terceiro tergo.

Holótipo macho. Comprimento aproximado 7,64 mm; comprimento da asa anterior a partir do esclerito costal $6,42 \mathrm{~mm}$; largura da cabeça 3,0 $\mathrm{mm}$. Tegumento preto exceto as seguintes áreas amarelas: clípeo, paroculares inferiores quase até o ápice das suturas sub-antenais, a seguir com recorte côncavo acompanhando os alvéolos antenais e em forma de estria fina reta dorsalmente, porém não chegando ao topo dos olhos (Fig. 2); um par de estrias interalveolares, incluindo as respectivas carenas e faixas nos lados do vértice prolongadas até a parte dorsal das genas (1/4). Antenas castanho-enegrecidas dorsalmente e castanho-pálidas no lado ventral, com mácula amarela alongada no escapo e de um amarelo-âmbar no primeiro flagelômero. Mesoscuto com faixas amarelas látero-basais; escutelo amarelo com a base e a margem pretas; axilas com mácula discal amarela. Tégulas castanhas; asas tingidas

1) Contribuição número 1384 do Departamento de Zoologia, Universidade Federal do Paraná.

2) Departamento de Zoologia, Universidade Federal do Paraná. Caixa Postal 19020, 81531-980 Curitiba, Paraná, Brasil. Bolsista do CNPq. 
de castanho; pernas castanhas, as anteriores com as tíbias e basitarsos castanho-pálidos; as medianas com mácula amarela estreita nas tíbias e as posteriores com amarelo-pálido na face externa dos basitarsos. Tergos pretos com as seguintes áreas amarelas: máculas ovaladas nos flancos do primeiro tergo, faixa estreita no segundo, um pouco mais larga nos flancos e prolongada na face ventral; do terceiro tergo ao distal a faixa amarela aumentando gradativamente. Primeiro e segundo tergos com o terço distal castanho, no terceiro a margem castanha mais estreita, quarto e quinto com margem translúcida amarelada, nos demais castanha e muito estreita. Segundo esterno com pequenas nódoas laterais amarelas.

Pilosidade branca, longa na cabeça, mesepisternos, parte das pernas e nos esternos; creme no mesoscuto, face ventral das tíbias, nos tarsos e tergos.

Clípeo grosso-pontuado, sem carena (Fig. 2); supraclipeal sem área lisa mediana; genas um pouco mais estreitas que os olhos quando vistas de perfil, com pontos grandes como os dos mesepisternos e carena justaorbital curtíssima; tégulas brilhantes, com pontos no terço basal, restante liso; mesoscuto com pontos grandes brilhantes, as cristas entre os pontos um pouco achatadas e foscas; escutelo com pontos grandes brilhantes, como no mesoscuto; tergos com pontuação fina, mais densa no basal, no segundo com os pontos separados por espaços maiores, cerca de um diâmetro de ponto, o terceiro com grandes espaços entre os pontos e nos dois seguintes com os intervalos um pouco menores.

Variações nos machos. Um dos parátipos sem a faixa amarela no segundo tergo, somente com nódoas laterais (Fig. 1); outro parátipo, também com as nódoas laterais amarelas no segundo tergo e as máculas amarelas nas pernas assim distribuídas: nas anteriores, mácula subapical alongada no fêmur e discal na face externa da tíbia; nas medianas, mancha discal na face posterior do fêmur e apical na tíbia; nas posteriores, mácula apical na tíbia.

Alótipo fêmea. Comprimento aproximado $9,20 \mathrm{~mm}$; comprimento da asa anterior a partir do esclerito costal $6,92 \mathrm{~mm}$; largura da cabeça $3,20 \mathrm{~mm}$. Tegumento preto excetuando as seguintes áreas amarelas: estrias paroculares delgadas, com uma pequena projeção angulosa na altura dos alvéolos antenais e a partir daí um pouco mais largas chegando quase até o topo dos olhos, a ponta dorsal mais afastada dos olhos; estrias interalveolares com os bordos paralelos medialmente e mais largas na parte dorsal aos alvéolos; faixa fragmentada na metade posterior do vértice, prolongada até o terço dorsal das genas. Antenas enegrecidas dorsalmente e castanhas na face ventral, segundo flagelômero amarelo-âmbar. Mesosoma como no macho, pernas sem manchas amarelas. Tergos como no macho, diferem pela margem translúcida amarelada larga do terceiro ao quinto (Fig. 3) e pelo colorido amarelo-ferrugíneo das faixas, segundo tergo com faixas laterais fragmentadas e amplamente separadas no meio, resultando num par de máculas dorsais muito estreitas e as laterais tão largas quanto as nódoas do tergo basal; do terceiro ao quinto como no macho e o sexto tergo amarelo-ferrugíneo com orla preta estreita.

Pilosidade branca e creme, pouco conspícua no mesoscuto; escopa branca. Clípeo e demais estruturas como no macho. 

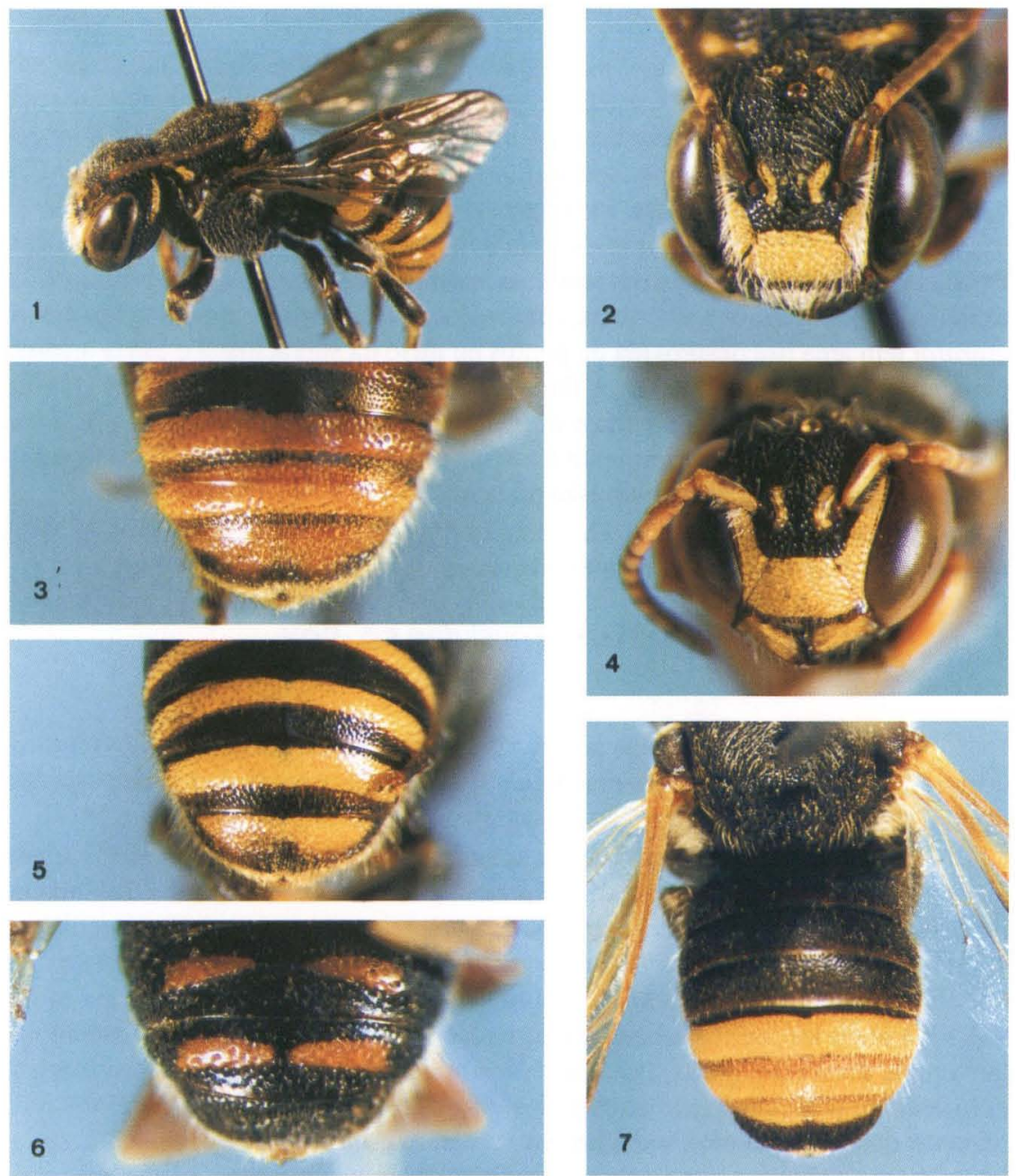

Figuras 1-7. (1-3) Anthodioctes ayalai sp. nov.: (1) parátipo macho em vista de perfil, (2) cabeça do holótipo, (3) tergos do alótipo fêmea; (4) Moureanthidium bahianum, cabeça do macho; (5) Anthodioctes misiutae sp. nov., tergos do holótipo fêmea; (6) Antodioctes rosanae sp. nov., tergos distais do holótipo fêmea; (7) Ananthidium dilmae, parte do mesosoma e tergos da fêmea.

Holótipo macho. MÉxICO, Veracruz, Fortin: 30.IV.1964, T.B. Mitchell leg. Alótipo fêmea e dois parátipos machos da mesma localidade do holótipo, os parátipos coletados em 27.IV.1964 e 29.IV.1964; depositados na Coleção Pe. J.S. Moure (DZUP). Todos os exemplares coletados em Bidens L. [Asteraceae].

Comentários. Pela chave de URBAN (1999a) o macho de A. ayalai chegaria ao item 24 juntamente com $A$. cerradicola, do Mato Grosso, Brasil e $A$. xilitlae Urban, 1999, de San Luis Potosi, México. Quanto aos machos, o de A. xilitlae é facilmente 
reconhecido pelas genas com área lisa desprovida de pontos atrás da carena justaorbital; o macho de $A$. cerradicola tem as tégulas denso-pontuadas e quase foscas, o mesoscuto com pontuação diferenciada no disco, com pontos grandes foscos intercalados irregularmente com pontos de tamanho reduzido, escutelo com esculturação fosca e de difícil visualização e pontuação densa nos tergos. A fêmea de $A$. ayalai, na mesma chave, iria ao item 23 saindo com A. cerradicola e A. moratoi Urban, 1999, do Amazonas, Brasil. A fêmea de $A$. cerradicola tem duas nódoas amarelas no clípeo, estria amarela retilínea nas paroculares e as tégulas, o mesoscuto e o escutelo como o macho; a de $A$. moratoi tem área lisa desprovida de pontos no meio da supraclipeal e estria amarela parocular alargada ventralmente. A fêmea de A. xilitlae, descrita por URBAN (1999b) tem carena genal justaorbital curta e irregular, chegando ao meio da gena e área lisa desprovida de pontos posteriormente à carena; na chave de URBAN (1999a) iria até o item 18, entrando em uma sub-divisão do item 19.

Etimologia. Dedicado ao Dr. Ricardo Ayala, Estación de Biología Chamela, Universidad Nacional Autónoma de México.

\section{Anthodioctes misiutae sp. nov.}

Fig. 5

Diagnose. Fêmea com as genas, vistas de perfil, tão largas quanto os olhos; com carena justaorbital apenas marcada e sem área desprovida de pontos; escutelo preto e com pontuação conspícua; faixas amarelas nos tergos.

Holótipo fêmea. Comprimento aproximado 7,84 mm; comprimento da asa anterior a partir do esclerito costal $6,42 \mathrm{~mm}$; largura da cabeça $2,89 \mathrm{~mm}$. Tegumento predominante preto exceto as seguintes áreas amarelas: estrias paroculares retilíneas até o ápice dos olhos, quase tão largas como o escapo; estrias interalveolares um pouco divergentes dorsalmente e incluindo as respectivas carenas; nódoa muito reduzida junto ao ocelo mediano; faixa na área posterior do vértice estendendo-se até a parte dorsal das genas (cerca de 1/4) e nódoa discal nas mandíbulas. Antenas com escapo, pedicelo e face ventral dos dois flagelômeros basais amarelo-ruivos, restante dos flagelômeros inteiramente castanho-escuros. Mesoscuto com faixas látero-basais amarelas estreitas e nódoa discal amarela nas axilas. Asas tingidas de castanho, veias enegrecidas; tégulas ferrugíneo-acastanhadas. Pernas castanho-enegrecidas, tíbias anteriores com a face ventral amarelo-arruivada e as medianas com a face ventral castanho-pálida. Tergos pretos com as seguintes áreas amarelas: nódoas pequenas nos lados do tergo basal, segundo tergo com faixas laterais muito finas e um pouco irregulares separadas por distância maior que o escapo; terceiro ao quinto tergo com faixa discal, distintamente mais larga no quinto; sexto tergo em grande parte amarelo com orla preta estreita, porém alargada no meio (Fig. 5). Base e margem dos tergos preta a castanho-enegrecida, no sexto um pouco mais larga médio-apicalmente, resultando em borda bissinuosa na mácula amarela; esternos castanho-escuros com faixas largas e irregulares amarelo-ruivas.

Pilosidade pouco conspícua, genas com pêlos brancos lisos; mesoscuto e tergos com pêlos mais curtos que meio diâmetro de ocelo, esbranquiçados e sem aspecto lanceolado. 
Clípeo com linha mediana elevada, irregular, formada pelos espaços entre os pontos; supraclipeal sem área desprovida de pontos; genas largas como os olhos, de perfil, com carena justaorbital apenas marcada pelos limites dos pontos e sem área lisa posteriormente à mesma. Mesoscuto e estutelo com pontos bem delimitados, no escutelo separados por cristas agudas e no mesoscuto, por espaços planos. Três primeiros tergos denso-pontuados, os pontos pequenos quando comparados aos dos tergos seguintes, nos dois basais mais densa e no terceiro os pontos separados por espaços de até um diâmetro de ponto; quarto e quinto tergos com pontos rasos e distintamente maiores.

Holótipo fêmea. Brasil, Paraná: Pinhão, Rio dos Touros, 15.I.1955, R. Misiuta leg. Parátipos: duas fêmeas com os mesmos dados do holótipo e uma de Santa Catarina, Seara (Nova Teutonia), XII.1955, F. Plaumann leg.; depositados na Coleção Pe. J.S. Moure (DZUP). Os espécimens de Pinhão foram coletados em armadilha de carne para moscas.

Comentários. Na chave de URBAN (1999a) a fêmea de A. misiutae iria até o item oito juntamente com A. salti (Schwarz, 1933) e A. mapirensis (Cockerell, 1927). A. salti tem carena genal justaorbital curta e sem área lisa posterior, pilosidade preta densa e alongada; ao passo que A. mapirensis tem carena genal justaorbital longa com larga área lisa posteriormente, as genas com pêlos ramificados, dispostos em três ou quatro fileiras partindo de pontos grandes e pilosidade lanceolada amarelo-fulva no dorso do mesosoma e do terceiro ao quinto tergo.

Etimologia. Dedicada à M. Sc. Ruth Misiuta, pela doação dos exemplares à Coleção Pe. J.S. Moure.

\section{Anthodioctes rosanae sp. nov.}

Fig. 6

Diagnose. Conhecida somente a fêmea; com máculas laterais amarelo-ferrugíneas do terceiro ao quinto tergo, sem faixas completas, o segundo tergo preto e o escutelo em grande parte amarelo.

Holótipo fêmea. Comprimento aproximado 7,25 mm; comprimento da asa anterior a partir do esclerito costal $5,76 \mathrm{~mm}$; largura da cabeça 2,84 $\mathrm{mm}$. Tegumento predominantemente preto, com exceção das seguintes áreas amarelo-ferrugíneas: estrias retilíneas ocupando a parte mediana das paroculares, começando ventralmente aos alvéolos antenais e terminando abaixo do topo dos olhos; duas estrias interalveolares incluindo as respectivas carenas, divergentes dorsalmente; faixas estreitas e curtas dos cantos do vértice às genas, não ultrapassando o comprimento do escapo. Antenas castanho-amareladas, escapo e pedicelo castanhos dorsalmente. Mesoscuto com máculas amarelo-ferrugíneas látero-basais; quase todo o escutelo e disco das axilas amarelo-ferrugíneos, o escutelo com área preta angulosa na base e o bordo também preto; pernas castanhas e asas tingidas de castanho. Metasoma preto com duas nódoas amarelo-ferrugíneas nos flancos do tergo basal; do terceiro ao quinto tergo com um par de máculas dorsais, mais largas dos lados e quase igualando o tamanho do escapo, no quinto separadas por área preta estreita (Fig. 6).

Pilosidade esbranquiçada, muito curta no mesoscuto, escopa branca.

Revta bras. Zool. 19 (Supl. 2): 151 - 158, 2002 
Clípeo com fina linha mediana lisa resultante dos espaços entre os pontos; supraclipeal grosso-pontuada, sem área lisa; genas de perfil tão largas quanto os olhos, sem carena justaorbital, com pontos grandes como os dos mesepisternos; tégulas brilhantes e quase sem pontos na metade posterior; face dorsal dos tergos com os pontos separados por espaços medindo um a quatro diâmetros de ponto.

Holótipo fêmea. MÉxICO, Yucatán, Merida, XII.1950, J. Lopez leg. Depositado na Coleção Pe. J.S. Moure (DZUP).

Comentário. Pela chave proposta por URBAN (1999a) iria até o ítem 15, sendo reconhecida pelas faixas amarelo-ferrugíneas nos lados do terceiro ao quinto tergo.

Etimologia. Dedicada à Dra. Rosana Moreira da Rocha, Departamento de Zoologia, Universidade Federal do Paraná.

\section{Anthodioctes lunatus (Smith, 1854)}

Anthidium lunatum Smith, 1854. Cat. Hym. Brit. Mus. II: 440.

Anthodioctes lunata; Moure, 1947. Publ. Avulsas Mus. Paranaense 3: 24.

Pela padronagem, Anthodioctes lunatus lembra A. moratoi Urban, 1999. Estas duas espécies são reconhecidas pela área pós-ocelar sem faixa amarela, escutelo e axilas amarelos e os tergos com faixas amarelo-pálidas. Entretanto, diferem nos seguintes caracteres: o macho de A. lunatus tem o clípeo inteiramente amarelo, carena genal curta e sem área lisa posterior, supraclipeal pontuada e os gonóstilos com alargamento subapical resultando num formato triangular; a fêmea não possui carena genal justaorbital; o macho de A. moratoi tem o clípeo amarelo só em parte, as genas com carena justaorbital até a metade dos olhos e larga área lisa junto à carena, supraclipeal com área discal lisa e os gonóstilos digitiformes sem alargamento subapical; a fêmea tem carena genal justaorbital longa formada pelas cristas dos pontos.

Variações. Foram vistos machos e fêmeas com as estrias genais amarelas desde a base das mandíbulas e outros com a estria amarela a partir da metade dorsal das genas até o vértice, porém não chegando à área pós-ocelar; o tergo distal do macho amarelo com margem preta ou com predominância da cor preta e o das fêmeas, amarelo com fina margem preta, ou com a metade apical preta ou ainda com o amarelo reduzido a duas máculas ovaladas; fêmeas com o clípeo ornado com duas nódoas amarelo-escuras obsoletas ou inteiramente preto.

Exemplares coletados em Óbidos e Belém, Pará, entre 1901 e 1919, por A. Ducke, têm as máculas amarelo-méleas ou amarelo-acastanhadas em vez de amarelas o que pode ter sido causado pelas condições de conservação e o terceiro tergo marcado inteiramente por pontos esparsos, separados por espaços medindo dois a quatro diâmetros de ponto. Nos exemplares coletados em Rio Branco, Acre, por E.F. Morato o terceiro tergo tem pontuação esparsa no disco e mais densa na margem.

Distribuição Geográfica. Brasıl, Pará: Guamá, Óbidos, Alter do Chão (aproximadamente a $30 \mathrm{~km}$ de Santarém) [localidade-tipo grafada pelo autor como Alta de Chäa no Tapajos]. Nova ocorrência no Acre: Rio Branco. 


\section{Ananthidium dilmae Urban, 1990}

Fig. 7

Ananthidium dilmae Urban, 1990. Revta bras. Zool. 7 (1-2): 77.

Diagnose. Fêmea com máculas amarelas arredondadas nas paroculares, quarto e quinto tergos amarelos quase por inteiro, o sexto, amarelo na base e com larga margem preta.

Fêmea. Comprimento aproximado $9,30 \mathrm{~mm}$; comprimento da asa anterior a partir do esclerito costal $6,86 \mathrm{~mm}$; largura da cabeça $3,28 \mathrm{~mm}$. Tegumento predominantemente preto; cabeça com nódoa amarela arredondada nas paroculares inferiores e mácula também amarela na parte dorsal das genas; mandíbulas e antenas pretas; asas tingidas de ferrugíneo nos dois terços basais e enegrecidas no restante; terceiro tergo com pequenas máculas laterais amarelas nos flancos, quarto ao sexto amarelos com faixa enegrecida estreita na base e a margem translúcida amarelo-fulva no quarto e quinto tergos, o sexto com larga margem preta (Fig. 7).

Pilosidade esbranquiçada, mais longa na cabeça e mesosoma, curta e decumbente nos tergos, no quarto e quinto a pilosidade fina entremeada com pêlos curtos lanceolados; escopa creme. Pontuação densa nos tergos, os espaços menores que os pontos.

Comentário. Conhecidas somente duas espécies, a fêmea de Ananthidium inerme (Friese, 1908) tem os artículos basais das antenas e grande parte das pernas ferrugíneos, as asas tingidas de castanho e somente o pterostigma amarelado, os dois tergos basais ferrugíneos e um par de nódoas ovaladas amarelas do segundo ao quinto tergo.

Distribuição geográfica. BRASIL, Minas Gerais: Belo Horizonte.

\section{Moureanthidium bahianum Urban, 1995}

Fig. 4

Moureanthidium bahianum Urban, 1995. Revta bras. Zool. 12 (1): 41.

Diagnose. Macho com o clípeo amarelo, larga margem amarela no escutelo e nas axilas, e larga margem translúcida esbranquiçada do terceiro ao quinto tergo.

Macho. Comprimento aproximado 6,86 mm; comprimento da asa anterior a partir do esclerito costal $6,46 \mathrm{~mm}$; largura da cabeça $2,5 \mathrm{~mm}$. Tegumento preto exceto as seguintes áreas amarelas: as mandíbulas excetuando os dentes; todo o clípeo, máculas nas paroculares dos lados do clípeo até pouco acima dos alvéolos e ai mais estreitas; um par de estrias interalveolares incluindo as respectivas carenas (Fig. 4); faixa no vértice, atrás dos olhos e dos ocelos. Antenas com escapo amarelo ventralmente, pedicelo e flagelômero basal ferrugíneos, do segundo ao nono flagelômero amarelo-ocre, os artículos com área basal castanho-clara, demais flagelômeros castanho-enegrecidos; dorsalmente ferrugíneos do escapo ao terceiro flagelômero e castanhos os restantes. Mesoscuto com máculas laterais amarelas em "L" invertido, escutelo e axilas com larga margem amarela, lados do escutelo com bordas translúcidas. Pernas com coxas e trocanteres castanhos, demais artículos ferrugíneos com máculas amarelas grandes nos fêmures e tíbias das pernas anteriores e media-

Revta bras. Zool. 19 (Supl. 2): 151 - 158, 2002 
nas, as máculas reduzidas nas pernas posteriores. Tergos com as máculas amarelas assim distribuídas: faixas laterais no primeiro, nódoas nos flancos do segundo, faixa discal no terceiro e quarto; quinto e sexto tergos com o amarelo predominando, com faixa basal preta estreita; tergo distal com margem amarela. A partir do terceiro tergo com o bordo translúcido largo amarelo-esbranquiçado. Esternos castanhos, o segundo com máculas amarelo-pálidas nos lados ou inteiramente castanho.

Coxas posteriores com lâmina dentiforme na metade basal, dobrada paralelamente ao contorno da coxa, com a ponta delgada.

Comentário. Muito parecido com o macho de M. subarenarium (Schwarz, 1933) que também tem lâmina basal nas coxas posteriores. Em M. subarenarium o clípeo é amarelo com orla preta junto à sutura epistomal, muito fina junto ao ramo transversal e alargando para os lados até as fóveas tentoriais, as antenas têm os cinco flagelômeros distais castanhos; escutelo com o bordo amarelo mais estreito que o diâmetro do ocelo ou reduzido a pequenas faixas laterais e os tergos com larga margem enegrecida.

Distribuição geográfica. BRASIL, Bahia: Vitória da Conquista.

\section{REFERÊNCIAS BIBLIOGRÁFICAS}

Urban, D. 1999a. Espécies novas e notas sobre Anthodioctes Holmberg (Hymenoptera, Apoidea, Megachilidae). Revta bras. Zool. 16 (supl. 1): 135-169.

. 1999b. Gênero novo e espécies novas de Anthidiinae e nota taxonômica (Hymenoptera, Megachilidae). Acta Biol. Par., Curitiba, 28 (1-4): 159-167.

Recebido em 12.IX.2002; aceito em 22.XI.2002. 